\title{
ÍNDICE DE CONDIÇÃO DE VIDA E DISTRIBUIÇÃO GEOGRÁFICA DOS CASOS DE COVID -19 EM FOZ DO IGUAÇU (PR) - PERÍODO MARÇO-SETEMBRO 2020
}

\section{LIFE CONDITION INDEX AND GEOGRAPHICAL DISTRIBUTION OF COVID 19 CASES IN FOZ DO IGUAÇU (PR) - PERIOD MARCH-SEPTEMBER 2020}

\author{
Diego Moraes Flores \\ Professor adjunto do Instituto Latino-Americano de Tecnologia, Infraestrutura e Território - ILATIT \\ Universidade Federal da Integração Latino-Americana \\ https://orcid.org/0000-0001-9485-0409 \\ diego.flores@unila.edu.br \\ Carmen Justina Gamarra \\ Professora adjunta do Instituto Latino-Americano de Ciências da Vida e da Natureza - ILACVN \\ Universidade Federal da Integração Latino-Americana- UNILA \\ https://orcid.org/0000-0003-4029-3859 \\ carmen.gamarra@unila.edu.br \\ Camila Meireles Fernandes \\ Mestranda no Programa de Pós-Graduação em Saúde Pública \\ Universidade de São Paulo (USP) \\ https://orcid.org/0000-00015453-8744 \\ cahhmeireles@gmail.com \\ Angela Paredes Salavaldez \\ Bióloga - Universidade Federal da Integração Latino-Americana \\ http://lattes.cnpq.br/8823398560150389 \\ anghela.paredes@gmail.com
}

\begin{abstract}
RESUMO
Com o advento da COVID - 19, pesquisas para conter a sua dispersão são cada vez mais necessárias e imediatas. Relacionar índices socioeconômicos e casos de notificação da doença, em um recorte de tempo e espaço é uma forma de conhecer o padrão de distribuição desta geograficamente e planejar ações para tomada de decisão. Este trabalho aplicou índice de condição de vida (ICV), elaborado a partir dos setores censitários do Censo de 2010 do IBGE e correlacionou-o aos casos de notificação de COVID - 19, utilizando um SIG (Sistema de Informações Geográficas) para o período de março a setembro de 2020, referente ao município de Foz do Iguaçu (PR). Dentre os principais resultados, obteve-se ICV relativamente baixo para os setores censitários que compõem o município $(0.1-0.3)$. A sobreposição dos dados das notificações absolutas e de concentrações de casos de COVID - 19, por setor censitário indicou proximidade geográfica entre aqueles que apresentaram ICV mais elevado $(0.4-0.6)$ e seus setores circunvizinhos mais baixos $(0.1-0.3)$. A análise das principais comorbidades associadas à COVID - 19 indicou também proximidade entre os setores de ICV alto e os seus contíguos de ICV baixo. Diferenças pontuais entre algumas áreas da cidade foram observadas.
\end{abstract}

Palavras-chave: ICV. COVID - 19. Setores censitários.

\begin{abstract}
With the advent of COVID - 19, research to contain its dispersion is increasingly necessary and immediate. Relating socioeconomic indexes and cases of notification of the disease, in a cut of time and space is a way to know the distribution pattern of this geographically and plan actions for decision making. This work applied the life condition index (ICV), elaborated from the census sectors of the 2010 IBGE Census and correlated it to the cases of notification of COVID - 19, using a GIS (Geographic Information System) for the period of March to September 2020, referring to the municipality of Foz do Iguaçu (PR). Among the main results, a relatively low ICV was obtained for the census sectors that make up the municipality $(0.1-0.3)$. The overlapping
\end{abstract}

Recebido em: 05/11/2020

Aceito para publicação em: 08/02/2021. 
of data from absolute notifications and COVID - 19 case concentrations by census sector indicated geographical proximity between those with the highest ICV $(0.4-0.6)$ and their lowest surrounding sectors $(0.1-0.3)$. The analysis of the main comorbidities associated with COVID 19 also indicated proximity between the high ICV sectors and their contiguous low ICV sectors. Point differences between some areas of the city were observed.

Keywords: ICV. COVID - 19. Census sectors.

\section{INTRODUÇÃO}

Desde a primeira constatação da COVID-19, em dezembro de 2019, em Wuhan (China) a doença causada pelo novo coronavírus (SARS-CoV-2), tem apresentado quadros clínicos variados de infecções assintomáticas a mais graves. De acordo com a Organização Mundial de Saúde (OMS), cerca de $80 \%$ dos pacientes com COVID-19 podem ser classificados como assintomáticos ou oligossintomáticos (poucos sintomas). Outros $20 \%$ dos casos detectados, necessitam de atendimento hospitalar por apresentarem dificuldade respiratória, dos quais, aproximadamente $5 \%$ podem necessitar de suporte ventilatório (BRASIL, 2020a).

No mundo todo, governos e instituições envolvidas buscam a elaboração de protocolos e intervenções com o intuito de impedir a transmissão viral, controlando a propagação do vírus nos territórios de seus domínios constitucionais. Horton, (2020) afirma que os modelos destinados a compreender a situação epidêmica não são simples, pois, se enquadram em duas categorias de doenças interagindo em populações específicas - infecção com síndrome respiratória aguda grave (SARS-CoV-2) e uma série de doenças não transmissíveis (DNTs).

Horton, (2020) credita que as condições de vida dos diversos grupos sociais, de acordo com padrões de desigualdade existentes, em nossas sociedades tendem a agravar a intensidade da doença, potencializando os efeitos adversos de cada uma em separado. O autor utiliza a ideia de sindemia (e não pandemia) para explicar a situação vigente, conceito este que tem em seu significado a combinação entre os termos: sinergia e pandemia. Sindemia foi inicialmente cunhado por Merrill Singer (SINGER, 1996; 2003; 2009; 2012; 2017), que introduziu o conceito a fim de identificar uma situação específica de propagação de doenças, onde pelo menos, duas ou mais estejam em processo de interação, causando danos maiores do que apenas a união destas.

Conforme a definição, a COVID - 19 é potencializada em função de uma variedade de condições préexistentes (diabetes, câncer, problemas cardíacos entre outros) com resultados distintos e adversos em comunidades menos desfavorecidas e de baixa renda. Horton (2020), em concordância a esta compreensão interativa, explicita que os fatores estruturais que dificultam o acesso dos pobres à saúde ou a uma alimentação adequada deveriam ser direcionados aos cuidados das DNTs:

[...] uma sindemia não é apenas uma comorbidade, as sindemias são caracterizadas por interações biológicas e sociais entre condições e estados, interações que aumentam a suscetibilidade de uma pessoa a prejudicar ou piorar seus resultados de saúde. No caso da COVID-19, atacar as DNTs será um pré-requisito para uma contenção bem-sucedida (HORTON, 2020, pg. 1).

Acredita-se que modelo teórico-metodológico de territorialização em saúde existente no Brasil foi construído com base no reconhecimento do território, conforme a organização das relações entre condições de vida da população e o acesso às ações e aos serviços de saúde (TEIXEIRA et al., 1998). Compreender, portanto, as situações-problema de uma população, em especial a temas ligados à saúde e seu território, indicando as interrelações espaciais existentes é uma forma de identificar caminhos de ação e tomada de decisão.

Desta forma, busca-se neste trabalho apresentar o índice de condição de vida (ICV) e analisar a sua relação com a distribuição dos casos de COVID-19 em Foz do Iguaçu (PR). 


\section{LOCALIZAÇÃO DA ÁREA DE ESTUDO}

Foz do Iguaçu é um município brasileiro do estado do Paraná, localizado no extremo oeste do terceiro planalto paranaense (Figura, 1). A oeste faz divisa com Ciudad Del Este (Paraguai) ao sul com Puerto Iguazú (Argentina) e norte e leste com municípios vizinhos da microrregião. Sua população é de 258.248 mil habitantes, segundo dados estimados do IBGE (2020a).

Figura 1 - Localização da área de estudo.

\section{Localização da Área de Estudo}

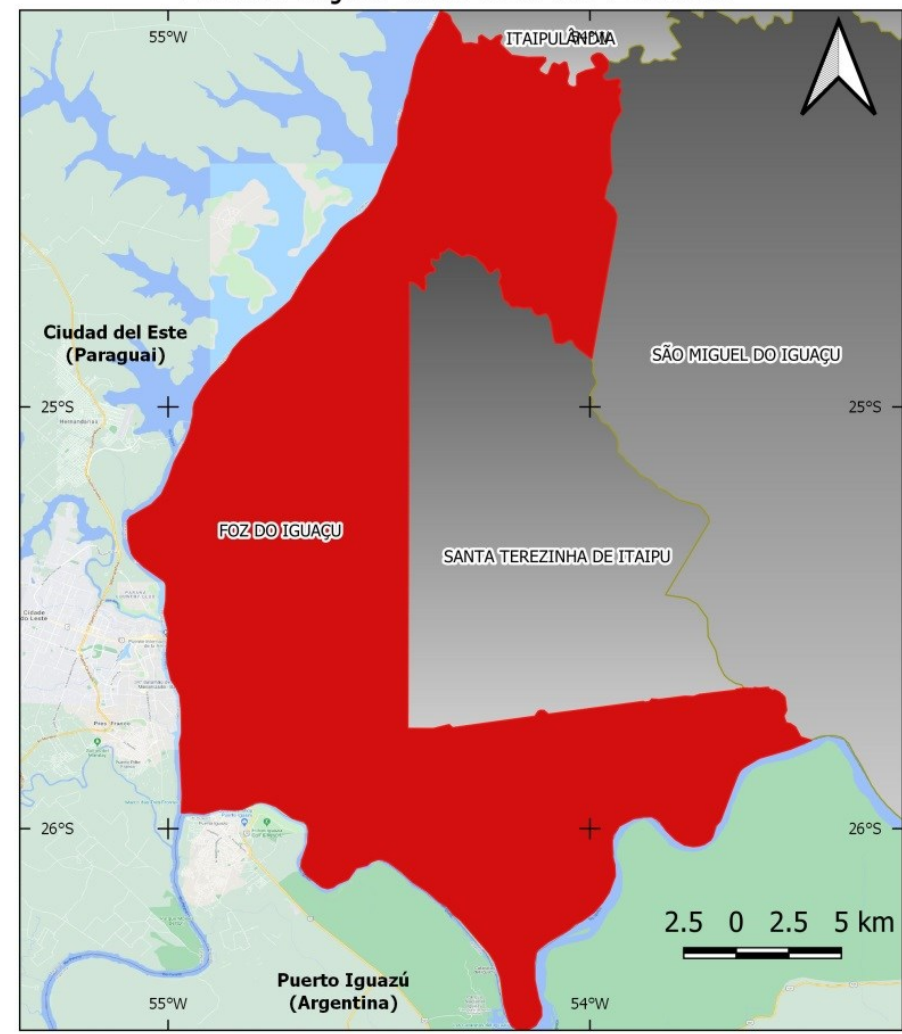

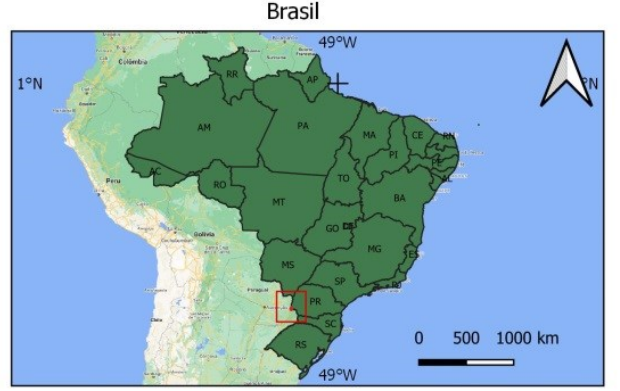

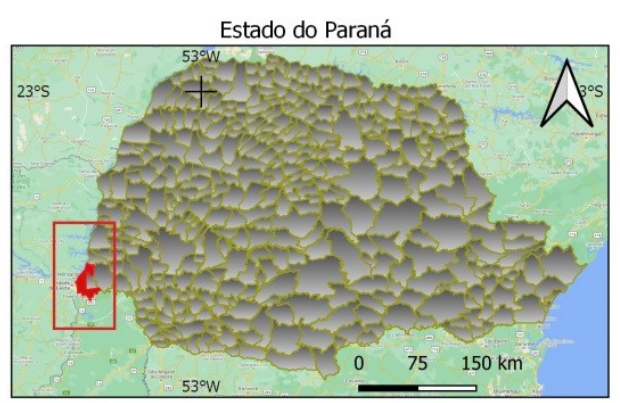

Legenda

Municípios (PR)
Estados

\section{Sistema de Coordenadas Geográicicas
DATUM SIRGAS 2000 EPSG: 4674 DATUM SIRGAS 2000 EPSG: 4674
Fonte Base Cartográfica: IBGE 2020 Base Map: Google Maps
Elaboraçăo: "Indicar após aceitaçăo do artigo"}

Fonte: IBGE (2020a); Base Maps (Google Maps). Organizado pelos autores.

Dentre os principais indicadores socioeconômicos, o município possui Índice de Desenvolvimento Humano Municipal (IDHM - 2010) de 0,751; Taxa de escolarização de 6 a 14 anos de idade (2010) de $\mathbf{9 6 , 4} \%$, PIB per capta (2017) de $\mathrm{R} \$ 50.990,89$, com salário médio mensal dos trabalhadores formais (2018) de 2,8 salários mínimos e renda per capta de $\mathrm{R} \$ 834,31$ (IBGE, 2020).

Por ser um dos principais polos turísticos do Brasil (turismo comercial e de procura por beleza cênica) e de concentração de serviços diversos em função da tríplice fronteira (Argentina e Paraguai, respectivamente ao sul e oeste), a cidade rapidamente passou a configurar nos índices de casos de COVID - 19 no estado, no início da pandemia. No dia 18 de março de 2020, verificou-se o primeiro caso de COVID-19 no município de Foz do Iguaçu e no dia 31 de março do mesmo ano, decretou-se estado de calamidade pública na cidade (FOZ DO IGUAÇU, 2020a).

Dados das Regiões de Influência das Cidades - REGIC (IBGE, 2018), que caracterizam os municípios brasileiros, segundo a procura da população para utilização de serviços de saúde de baixa, média e de alta complexidade, tanto em instituições públicas quanto particulares, permitiu identificar os municípios que possuem maior capacidade de gerar deslocamentos por atração da população de outros municípios em busca de bens e serviços. Segundo a publicação, Foz do Iguaçu (PR) é uma importante cidade polarizadora, quanto à procura (destino) por serviços de saúde (baixa - média complexidade, bem como, de alta complexidade). 


\section{PROCEDIMENTOS METODOLÓGICOS}

\section{Base dos dados socioeconômicos}

Para a construção do índice de Condição de Vida (ICV) do município de Foz do Iguaçu (PR) realizouse inicialmente pesquisa na base de informações do "Censo Demográfico de 2010: resultados do universo por setor censitário - documentação" (IBGE, 2010b). Como não houve censo no ano de 2020 (idealizado a cada 10 anos), foi necessária a utilização dos dados organizados para o decênio de 2010.

Nesta etapa inicial selecionaram-se as variáveis e descrição com nome da variável, por setor censitário, como no exemplo do quadro 1:

Quadro 1 - Exemplificação de uma variável do censo demográfico de 2010.

\begin{tabular}{|c|c|}
\hline Código da variável & Descrição do setor \\
\hline V001 & $\begin{array}{c}\text { Domicílios particulares permanentes ou pessoas } \\
\text { responsáveis por domicílios particulares permanentes }\end{array}$ \\
\hline
\end{tabular}

Fonte: IBGE (2010b).

O arquivo do universo do censo apresenta o código de identificação do setor, como também os códigos e os nomes de cada setor. Esta documentação inclui as notas metodológicas apresentadas na publicação, características da população e dos domicílios, além das informações técnicas relativas ao arquivo.

O uso das variáveis para a montagem do índice seguiu procedimentos observados na literatura com o tema em pesquisas do gênero (CASTELLANOS 1994; FUNDAÇÃO JOÃO PINHEIRO, 1996; WAQUIL, 2007; FARIAS, 2014; RAMBO et. al, 2015; SILVA, 2017; PNUD, 2020). A metodologia elenca a escolha de um número mínimo de variáveis que permitem a construção das dimensões de análise abordadas pelo Atlas de Desenvolvimento Humano no Brasil, sendo as principais dimensões: Renda, Educação, Infância, Habitação e Longevidade (PNUD, 2020).

As dimensões elencadas (quadro 2) para esta pesquisa visaram retratar ao máximo, a realidade municipal e obter uma interface com os temas ligados a saúde. Sendo assim, foram selecionadas as seguintes dimensões e variáveis para a montagem do ICV:

Quadro 2 - Variáveis utilizadas para a elaboração do ICV.

\begin{tabular}{|c|c|c|}
\hline Dimensões & Variáveis & Descrição \\
\hline \multirow[t]{5}{*}{ Educação } & $\begin{array}{c}\text { [Responsável02] V093 } \\
\text { Responsáveis alfabetizados }\end{array}$ & \multirow{5}{*}{$\begin{array}{c}\text { Para obter o número de responsáveis analfabetos utilizou-se os dados } \\
\text { de pessoas responsáveis para posterior rearranjo, com o número de } \\
\text { responsáveis alfabetizados. }\end{array}$} \\
\hline & $\begin{array}{l}\text { [Responsável02] V001 } \\
\text { Pessoas responsáveis }\end{array}$ & \\
\hline & Responsáveis analfabetos & \\
\hline & $\begin{array}{l}\text { [Responsável01] V093 } \\
\text { Mulheres responsáveis } \\
\text { alfabetizadas }\end{array}$ & \\
\hline & $\begin{array}{l}\text { [Responsável02] V201 } \\
\text { Homens responsáveis } \\
\text { alfabetizados }\end{array}$ & \\
\hline \multirow{4}{*}{$\begin{array}{l}\text { Demografia e } \\
\text { Longevidade }\end{array}$} & Pessoas de 0 a 5 anos & \multirow{4}{*}{$\begin{array}{l}\text { Para obter o número de pessoas de } 0 \text { a } 5 \text { anos utilizou-se os seguintes } \\
\text { códigos: [Pessoa13] V023, [Pessoa13] V024, [Pessoa13] V025, } \\
\text { [Pessoa13] V026, [Pessoa13] V027, [Pessoa13] V028, [Pessoa13] } \\
\text { V029, [Pessoa13] V030, [Pessoa13] V031, [Pessoa13] V032, } \\
\text { [Pessoa13] V033, [Pessoa13] V034, [Pessoa13] V035, [Pessoa13] } \\
\text { V036, [Pessoa13] V037, [Pessoa13] V038 e [Pessoa13] V039. Para o } \\
\text { número de pessoas com 65 anos o mais os seguintes códigos } \\
\text { [Pessoa13] V099, [Pessoa13] V100, [Pessoa13] V101, [Pessoa13] } \\
\text { V102, [Pessoa13] V103, [Pessoa13] V104, [Pessoa13] V105, } \\
\text { [Pessoa13] V106, [Pessoa13] V107, [Pessoa13] V108, [Pessoa13] } \\
\text { V109, [Pessoa13] V110, [Pessoa13] V111, [Pessoa13] V112, } \\
\text { [Pessoa13] V113, [Pessoa13] V114, [Pessoa13] V115, [Pessoa13] } \\
\text { V116, [Pessoa13] V117, [Pessoa13] V118, [Pessoa13] V119, }\end{array}$} \\
\hline & $\begin{array}{l}\text { [Responsável02] V002 } \\
\text { Pessoa responsável com } 10 \\
\text { anos de idade }\end{array}$ & \\
\hline & Pessoas de 65 anos a mais & \\
\hline & $\begin{array}{c}\text { Responsáveis de } 65 \text { anos a } \\
\text { mais }\end{array}$ & \\
\hline$d x$ & $10.14393 / \mathrm{Hy}$ & p. $161-180$ \\
\hline
\end{tabular}


Índice $=$ (valor observado para o indicador - pior valor) / (melhor valor - pior valor)

Realizado o procedimento de obtenção do índice para cada indicador selecionado do censo, obtevese por média simples um valor único de ICV dentre todos, para que estes pudessem representar a dimensão estabelecida inicialmente (figura, 2). O mesmo procedimento foi feito para a obtenção do ICV final.

Figura 2 - Fluxograma para obtenção do ICV dos setores censitários de Foz do Iguaçu (PR).

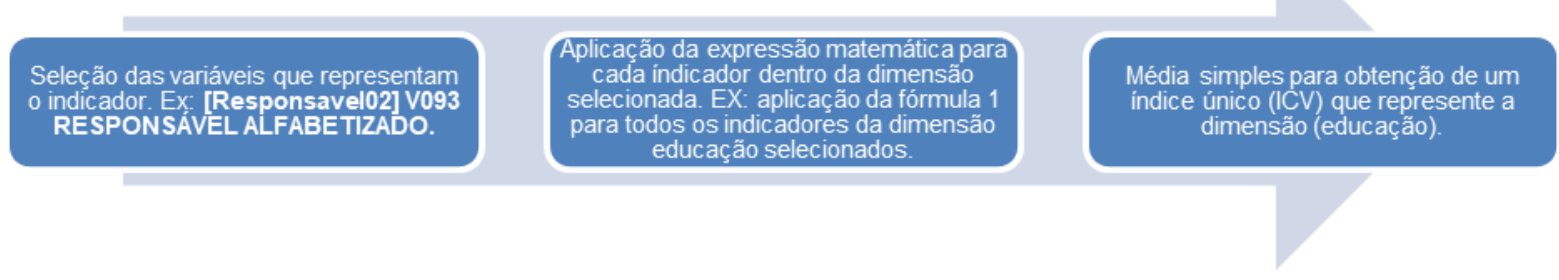

Fonte: (Organizado pelos autores).

\section{Dados de COVID - 19 de Foz do Iguaçu (PR) e Georreferenciamento para mapas}

Os dados pertencentes ao quadro epidemiológico do município foram obtidos através de consultas diretas ao sistema de notificação de casos suspeitos de COVID-19 da secretaria de saúde do estado do Paraná (PARANA, 2020); banco de dados do Sistema Único de Saúde - DATASUS (BRASIL, 2020b); do sistema de notificação de casos da prefeitura de Foz do Iguaçu (PR), bem como, dos boletins diários da mesma comarca (FOZ DO IGUAÇU, 2020b).

O tratamento e organização dos dados seguiram os seguintes procedimentos:

a) Tratamento em planilhas eletrônicas do número de notificações de COVID-19 no município de Foz do Iguaçu (PR) e seu agrupamento às colunas referentes a cada (CD_GEOCODI) setor censitário correspondente ao ICV criado.

b) Outros dados ligados às notificações tratados para o georreferenciamento foram:

- País residência; (UF) residência; município de residência; CEP de residência; logradouro residência; número residência; bairro residência. Cabe salientar que, como são passíveis de geolocalização, os dados não foram georreferenciados de forma a expor a localidade exata do notificado (Parecer $n^{\circ} 4.290 .232$ aprovado pelo Comitê de Ética em Pesquisa do Conselho Nacional de Saúde / Ministério de Saúde, sob o no do CAAE: 35443320.0.0000.9607 em 21/09/2020).

c) Através da criação de mapas de densidade (intensidade) "Kernel", o dado pontual foi transformado (via algoritmo Kernel) em informação para análise geográfica de comportamento de padrões. Isto permitiu as análises gerais, uma visão da intensidade do processo em todas as localidades do município.

d) Variáveis de dados clínicos coletadas:

- Organizou-se o quantitativo das comorbidades dos dados extraídos do Notifica COVID-19 e do banco de dados da Prefeitura de Foz do Iguaçu (PR). Foram contabilizados e tratados os valores de cada comorbidade em planilha eletrônica, com posterior tratamento estatístico para visualização dos percentuais totais para o município, para destaque daquelas de maior expressão.

- Foi realizado destaque das principais comorbidades, através de seleção por atributos, no software Qgis 3.10, e correlacionadas aos setores censitários (e bairros), além de comparação com os ICV's criados, identificando geograficamente a presenças destas em cada setor, referente aos notificados no recorte de tempo estipulado. 


\section{RESULTADOS E DISCUSSÕES}

\section{Índice de condição de Vida (ICV) - Foz do Iguaçu (PR) e correlação espacial com os dados de Notificados de COVID - 19}

A análise do ICV de Foz do Iguaçu (PR) para efeitos práticos foi realizada com observação da sobreposição dos polígonos dos bairros (FOZ DO IGUAÇU, 2013; 2018; 2019) sobre o conjunto de setores censitários correspondentes. A figura 3 abaixo identifica um primeiro recorte urbano, com ICV's extraídos para a cidade como um todo.

Figura 3 - Índice de Condição de Vida (ICV) da área urbana de Foz do Iguaçu (PR).

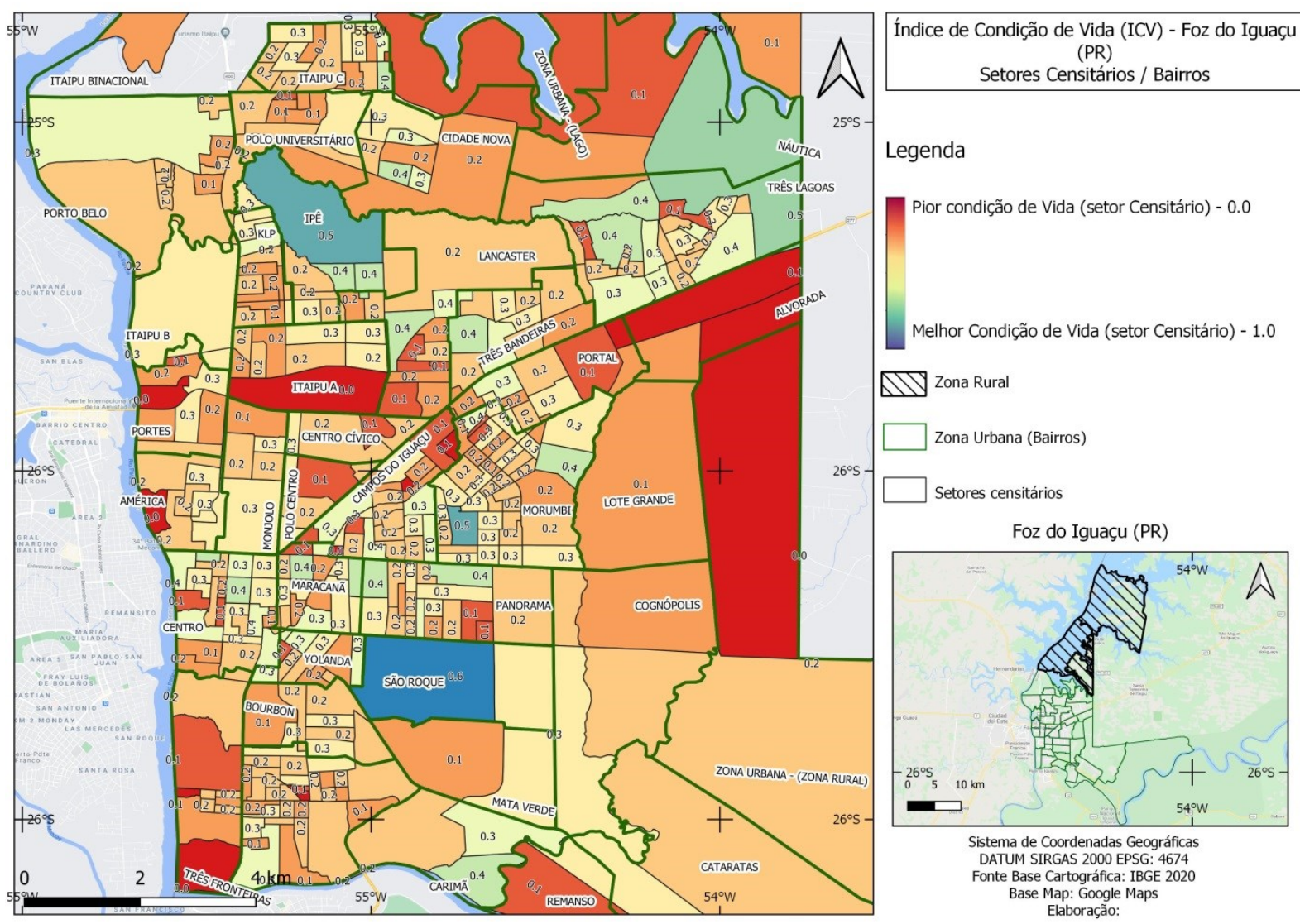

Fonte: IBGE (2020b); Base Maps (Google Maps). Organizado pelos autores.

As classes de melhor ICV $(0.4-0.6)$ restringem-se a setores concentrados em bairros centrais (Centro, Panorama Maracanã) ou ligados a bairros com presença de condomínios fechados, de alto poder aquisitivo de seus residentes em meio a residências de médio e baixo padrão (Ipê, Lancaster, Três Bandeiras).

Observando o conjunto de setores censitários e as classes atribuídas percebe-se um número maior de classes com valores mais baixos $(0-0.3)$ que se distribuem em todo o município. Atribui-se inicialmente esta configuração a uma possível defasagem dos dados (valores dos indicadores utilizados) que reportam a 2010 (censo) e que pode não expor por completo, a realidade existente em dias atuais. Outro fator importante que pode ser elencado é a existência de áreas com arborização e/ou espaços verdes e mesmo setores industriais, na transição zona urbana e rural, que compõem justamente parte dos setores que correspondem a pior condição $(0-0.1 /$ vermelho), mas que também englobam ICV's de 0.2 .

Além disso, a quantidade de residências, nestas áreas de transição (urbano-rural), com indicação de ICV's mais baixos apresentam menor densidade populacional, o que pode refletir no valor do ICV, a 
depender do conjunto de famílias e suas estruturas de vida (todas as dimensões juntas) existentes para o ano de 2010.

A figura 4 abaixo representam as situações onde o ICV muito baixo recaiu sobre setores censitários com alguma peculiaridade específica além da aplicação metodológica atribuída. Algumas situações foram aventadas em função do conhecimento das localidades e de seus usos mais comuns. São áreas com menor densidade de residências, áreas de lazer (chácaras e clubes náuticos), áreas de pequenos cultivos, de proteção ambiental ou áreas com pequenas instalações industriais.

Sendo neste caso, muito pequeno os valores que pudessem ser contabilizados nas variáveis do censo e que por final compuseram a confecção dos ICV's. Enquadram-se nesta situação, setores contidos nos seguintes bairros: Naútica / Itaipu Binacional; Itaipu A; Alvorada; Lote Grande, Cognópolis e Remanso (figura, 4).

Figura 4 - Setores censitários com ICV baixo e com alguma peculiaridade específica.
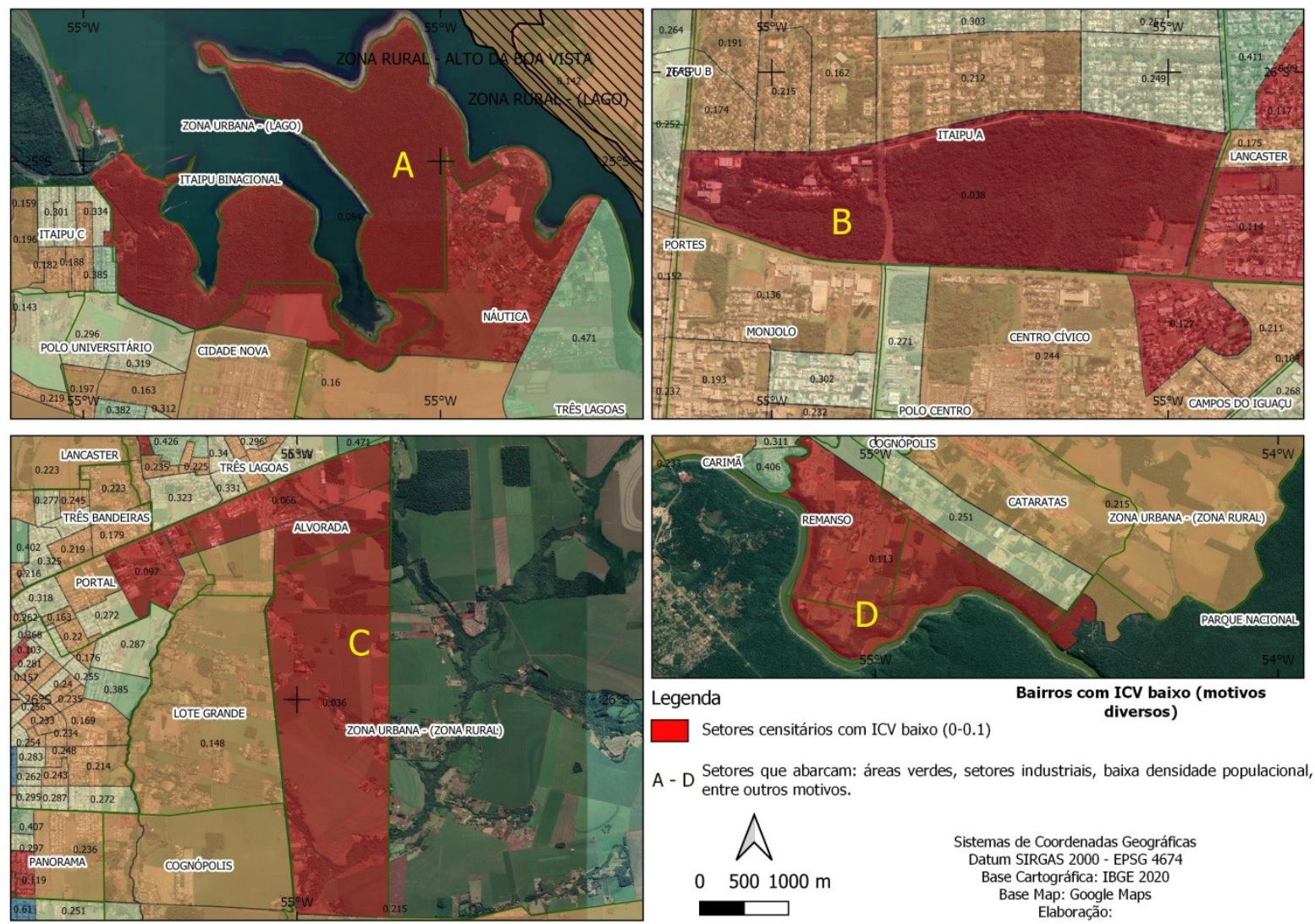

Fonte: IBGE (2020b); Base Maps (Google Maps). Organizado pelos autores.

Quando realizada a análise dos ICV's, a partir dos dados com recorte geográfico por bairros e seus respectivos setores censitários, a visualização das notificações de COVID-19 (dados sobrepostos) permite melhor interpretação da distribuição das mesmas sobre o território, no contexto de tempo pesquisado (Março-Setembro de 2020).

Observa-se, para a zona norte (figura 5), que os bairros Ipê, Itaipu A e C, Porto Belo, Cidade Nova e Lancaster, respectivamente, e seus setores censitários contidos apresentaram ICV entre 0.2 e 0.6 no geral. Em destaque, setores censitários do bairro Ipê (0.5) e a alguns centralizados no bairro Lancaster apresentaram valores mais altos de ICV's (0.4), em comparação aos bairros da própria Zona Norte; os demais ficaram entre ICV's de 0.1 a 0.3.

Considerando que a metodologia adotada permite valores até 1, o que seria uma condição ótima, os maiores valores observados para Foz do Iguaçu (PR), beirando apenas 0.6, mostra que em 2010, a 
condição de vida do município (considerando as variáveis elencadas para cada dimensão nesta pesquisa) não eram tão satisfatórias como um todo. Quando se observa os valores absolutos de notificações de COVID - 19 e a concentração dos casos por bairro e setor censitário, percebe-se que tanto os quantitativos absolutos, quanto as concentrações por área em cada setor indicam proximidade geográfica entre aqueles setores que apresentaram ICV mais elevado e os mais adjacentes (setores) com valores mais baixos $(0.1-0.3)$.

Como exemplo, cita-se o Bairro Ipê novamente, no qual se pôde estabelecer uma correlação geográfica em relação às notificações espacializadas. Os setores com ICV's 0.4 - 0.5 tiveram somados no período, mais de 200 notificações em relação aos seus setores censitários circunvizinhos com ICV's baixos, onde os valores mais altos de notificações em média, encontravamse próximos de 20 casos (ou pouco mais) por setor censitário, quando comparados aos de ICV mais alto, que apresentavam 30 ou mais por setor. A sobreposição dos mapas de calor ajuda a esta visualização de proximidade geográfica, entre os setores com ICV mais alto com aqueles de ICV mais baixo, bem como, a correlação com a concentração de notificados por setor censitário e bairros.

Contudo, afirmar quais foram os focos iniciais de contágio e propagação necessitaria de modelos de análise mais robustos (metapopulações), inclusive para formulações de projeções futuras de propagação da doença a partir da localização inicial.

Figura 5 - Recorte para os bairros e setores censitários da zona norte do município.

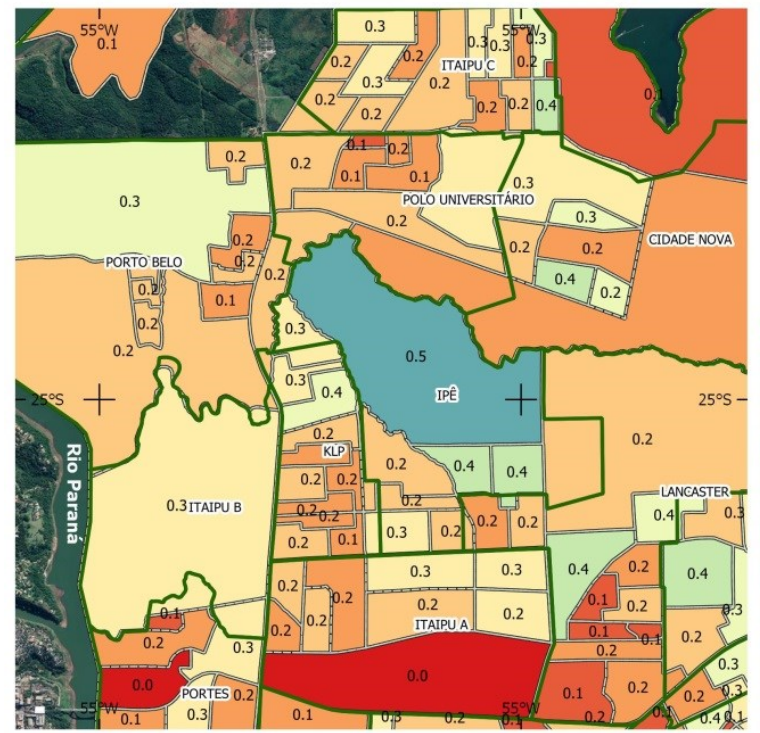

Legenda

Índice de condição de Vida_Setores censitários

ص $0-0,1$

च $0,1-0,1$

$\square 0,1-0,2$

口 $0,2-0,2$

吕 $0,2-0,3$

ص $0,3-0,4$

$0,4-0,4$

口 $0,4-0,5$

$0,5-0,5$

口 $0,5-0,6$

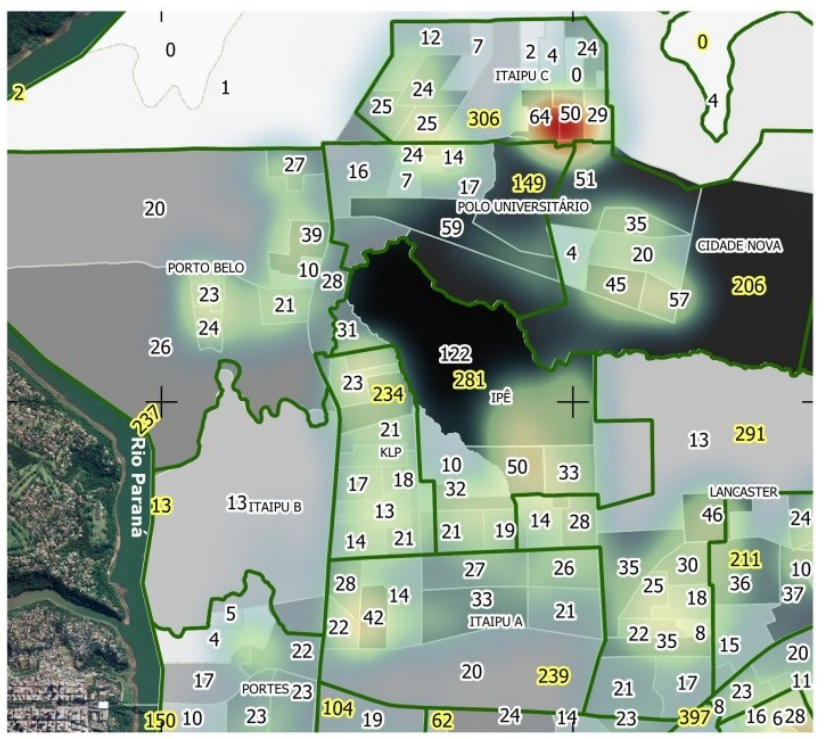

Zona Norte - ICV / COVID -19 (Bairros - Setores)
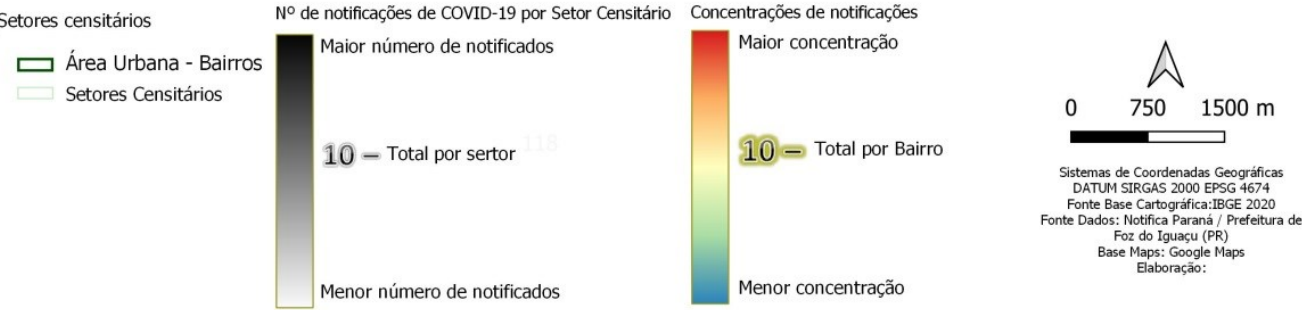

Fonte: IBGE (2020b); Base Maps (Google Maps). Organizado pelos autores.

Pesquisas do gênero, em cidades de maior porte, indicaram que a mobilidade urbana durante o período da pandemia, especificamente compreendendo o fluxo de circulação das pessoas na cidade, relacionadas à prestação de diversos serviços, influência de sobremaneira, a difusão espacial da COVID-19 (MARINO et al., 2020). 
Os demais bairros da zona norte, onde os ICV's são baixos ( $0.1-0.2$, no geral) foram observados também valores altos de notificados, como os: Cidade Nova (206), Porto Belo (237) e Itaipu A (239) e C (306). Ocorreu certa heterogeneidade na distribuição quando observados os setores individualmente.

A interpretação dos dados apenas permite inferir que o processo de contágio se distribuiu no tempo, na dinâmica habitual da cidade, com focos de notificados e sua concentração nos setores censitários com ICV's altos e baixo próximos entre si geograficamente, mas que também foram presentes nos setores com valores de ICV baixo, para a zona norte da cidade.

O bairro Polo Universitário, embora tenha apresentado valores totais (149) menores em comparação aos demais bairros, apresentou dois setores censitários, com alta concentração de notificados (59 e 51), sendo estes próximos geograficamente (limite) a outros (de outros bairros), onde o mapa de calor indicou concentração alta (Ipê e Cidade Nova, setores mais a oeste do bairro).

Outra inferência a partir desta última configuração é que as pessoas que possuem menor estrutura para condição de vida estão mais à mercê do contágio. Provavelmente, não terem os recursos suficientemente necessários para o confinamento, constatação já indicada em outras pesquisas e a notícias relacionadas (BEZERRA et al., 2020; GALINDO e ARROYO, 2020; GRAGNANI, 2020)

Analisando a zona nordeste (NE) do município na figura 6, observa-se semelhança com a zona norte quanto à proximidade geográfica de setores censitários com ICV entre 0.3 a 0.5 , em relação aos de valores entre $0.1-0.2$. Quando se considera o número de notificações e concentrações sobre os setores, observa-se certa distribuição heterogênea de notificados entre setores censitários com ICV mais alto aos mais baixos, mas também proximidade geográfica entre eles, quando se atribui o mapa de calor, que indica as concentrações.

Figura 6 - Recorte para os bairros e setores censitários da zona nordeste do município.

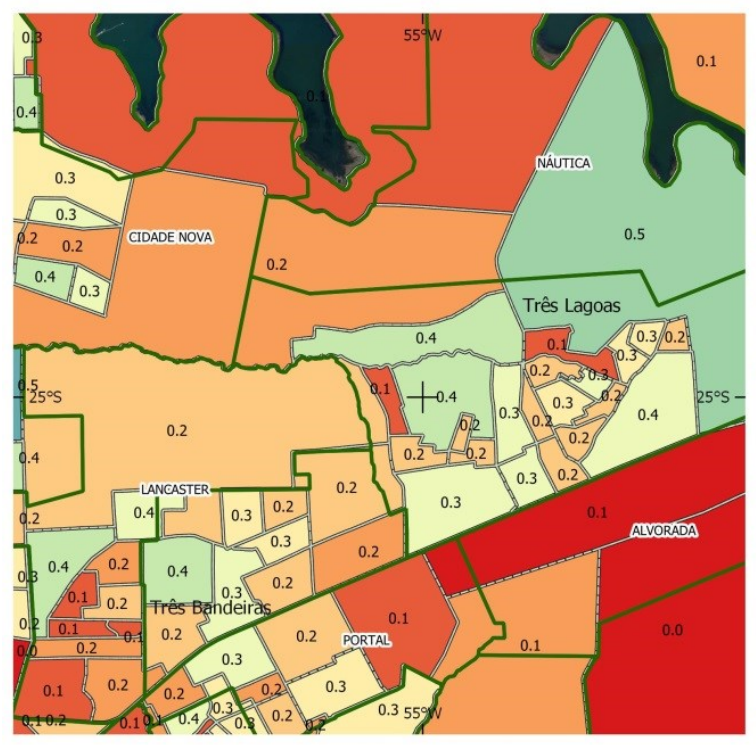

Legenda

Índice de condição de Vida_Setores censitários

$0-0,1$

$0,1-0,1$

勿 $0,1-0,2$

口 $0,2-0,2$

口 $0,2-0,3$

口 $0,3-0,4$

๑ $0,4-0,4$

$0,4-0,5$

曰 $0,5-0,5$

$0,5-0,6$

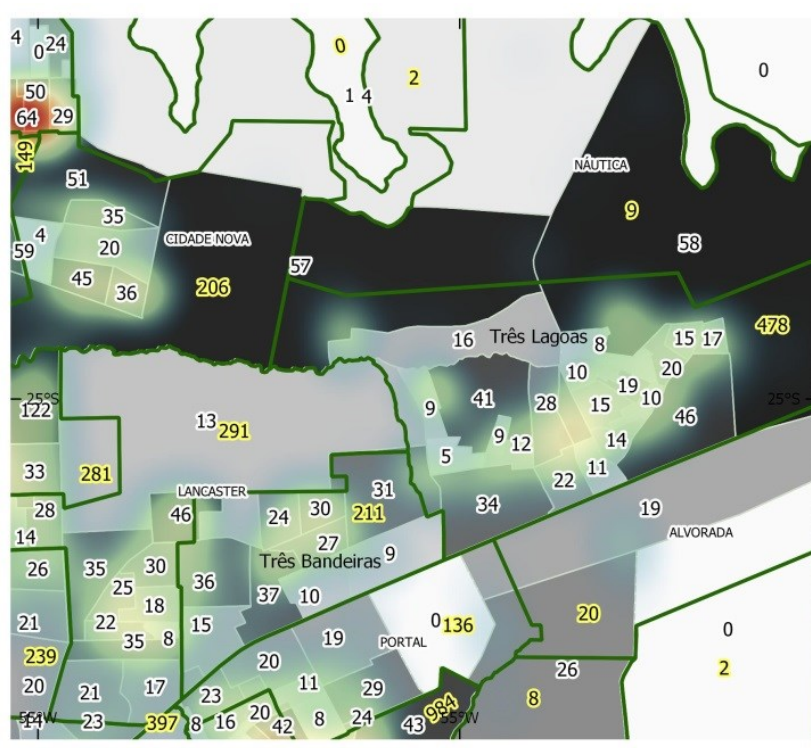

Zona Nordeste - ICV / COVID - 19 (Bairros - Setores)
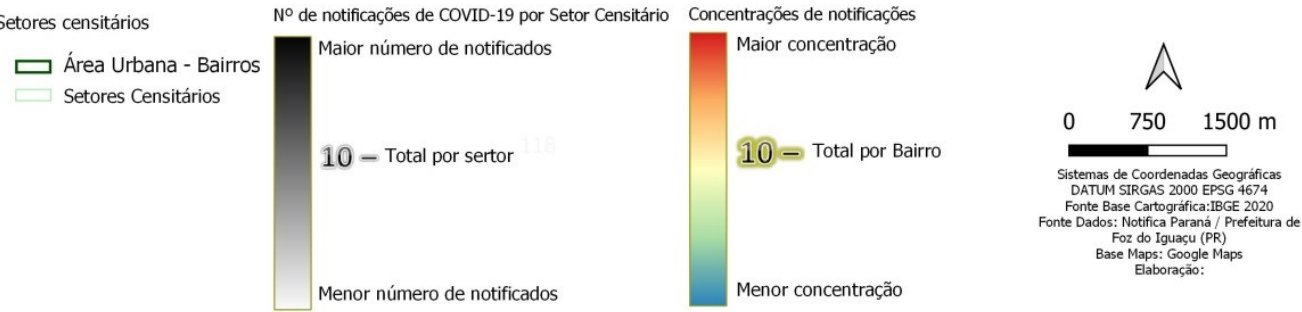

Fonte: IBGE (2020b); Base Maps (Google Maps). Organizado pelos autores. 
Os setores com valores de ICV mais alto, atribui-se a existência de condomínios de alto padrão em setores específicos, sobretudo, no bairro Três Bandeiras e chácaras de lazer no bairro Três Lagoas. O mesmo pode ser indicado, para os setores descritos na zona norte e que apresentavam ICV mais elevado.

Os setores com ICV mais baixo $(0.1-0.2)$ comportam moradias de médio e baixo porte. Nos bairros Alvorada e Portal, onde não há condomínios ou residências que indicam maior poder aquisitivo, o ICV retornou valores entre 0.1 a 0.3 . A concentração de casos foi maior, bem como, o número de notificados no Bairro Três Lagoas (478 no total do período), onde o ICV variou entre 0.1 a 0.5 , com configuração de proximidade geográfica semelhante e já descrita.

No bairro Naútica pela característica, de conter poucas residências, parte destas voltadas para o lazer esporádico, os ICV's mais baixos $(0.1-0.2)$ configuraram residências e famílias de menor estrutura de condição de vida para o ano de 2010, atreladas a pequenas produções de subsistência e/ou residências de trabalhadores rurais de menor poder aquisitivo. Quando do valor mais alto (0.5), provavelmente se caracterizam como residências de famílias, com melhor condição de vida, que usufruem do espaço esporadicamente, para lazer e/ou áreas de pequenos clubes náuticos.

Os setores que se encontram nesta porção nordeste do município, contidos nos bairros Lancaster e Cidade Nova, apresentaram ICV baixos $(0.1-0.2)$, com concentrações de notificados mais elevadas na transição Lancaster/Três Bandeiras, e pronunciada valor (57) na porção mais a leste do bairro Cidade Nova. Também nestes bairros ocorreram maiores concentrações de notificados, quando de um setor com ICV mais alto próximo de um mais baixo.

Na zona Leste do município (figura, 7) que comportam os bairros Morumbi, Panorama, Lote Grande, Campos do Iguaçu e parte do Portal, quanto aos ICV's, preponderam os valores de 0.1 a 0.3 , com pequenos setores com valores de 0.4 no bairro Panorama e um no bairro Morumbi $(0.5)$.

Figura 7 - Recorte para os bairros e setores censitários da zona leste do município.

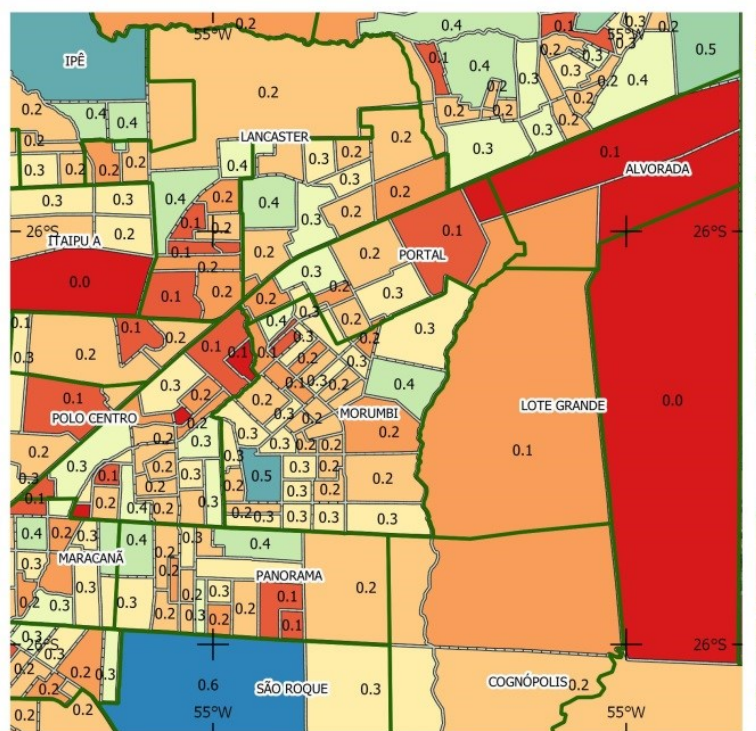

Legenda

Índice de condição de Vida_Setores censitários

$0-0,1$

口 $0,1-0,1$

ص $0,1-0,2$

$0,2-0,2$

口 $0,2-0,3$

口 $0,3-0,4$

$0,4-0,4$

$0,4-0,5$

$0,5-0,5$

$0,5-0,6$

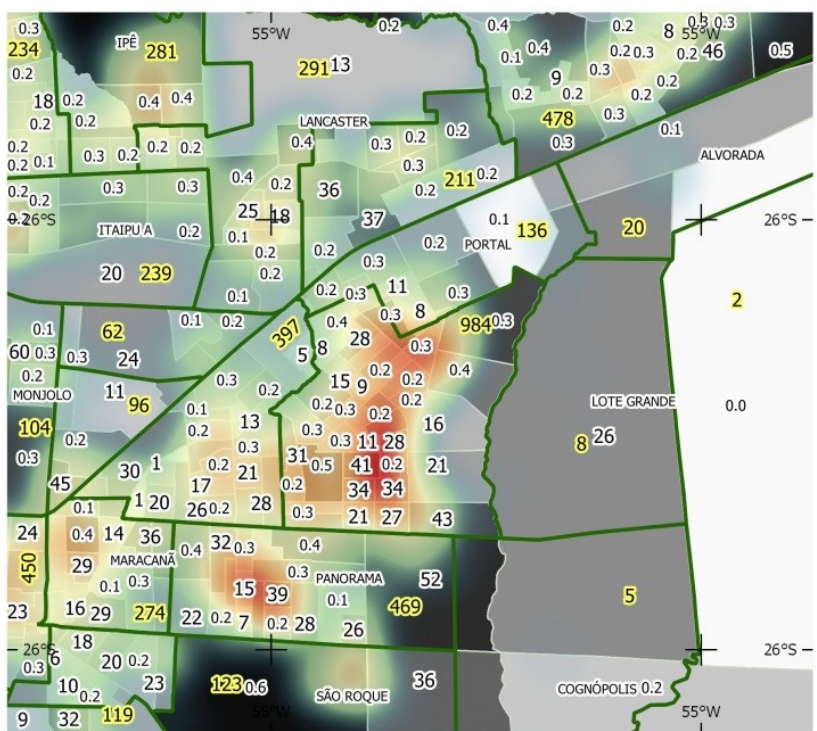

Zona Leste - ICV / COVID - 19 (Bairros - Setores)
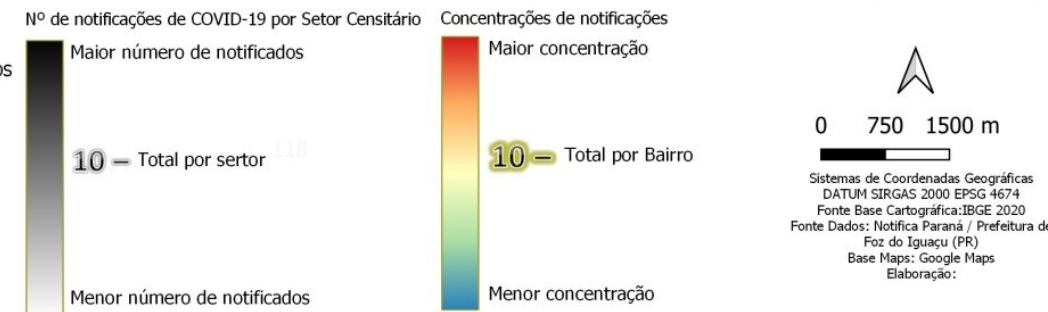

Fonte: IBGE (2020b); Base Maps (Google Maps). Organizado pelos autores. 
Destaca-se o bairro Morumbi, com o maior número de notificados (984) e maiores concentrações de notificados sobre os setores censitários no período analisado. Sendo novamente, observada a correlação, ICV alto próximo de ICV baixo, maior número de notificados e concentrações.

As concentrações também foram elevadas no bairro Panorama nos setores de menor ICV (0.1), como observado anteriormente, apresentam proximidade geográfica com outros setores de ICV mais elevado (setores dos bairros do São Roque, próprio Panorama e Maracanã).

No bairro Lote Grande e parte deste, há áreas com pouca densidade de residências e outros usos, por isso do ICV baixo (0.1), com poucos notificados no período (8) e menores concentrações de casos sobre os setores censitários.

A região central do município e a porção oeste comportam os seguintes bairros: Portes, América, Centro, Monjolo, Polo Centro, Maracanã, Yolanda, Centro Cívico, Bourbon, São Roque e Mata Verde. Os melhores ICV's para estas áreas da cidade $(0.6$ - 0.4) encontram-se nos bairros São Roque, Centro e Maracanã (figura, 8)

Figura 8 - Recorte para os bairros e setores censitários da zona central e oeste do município.

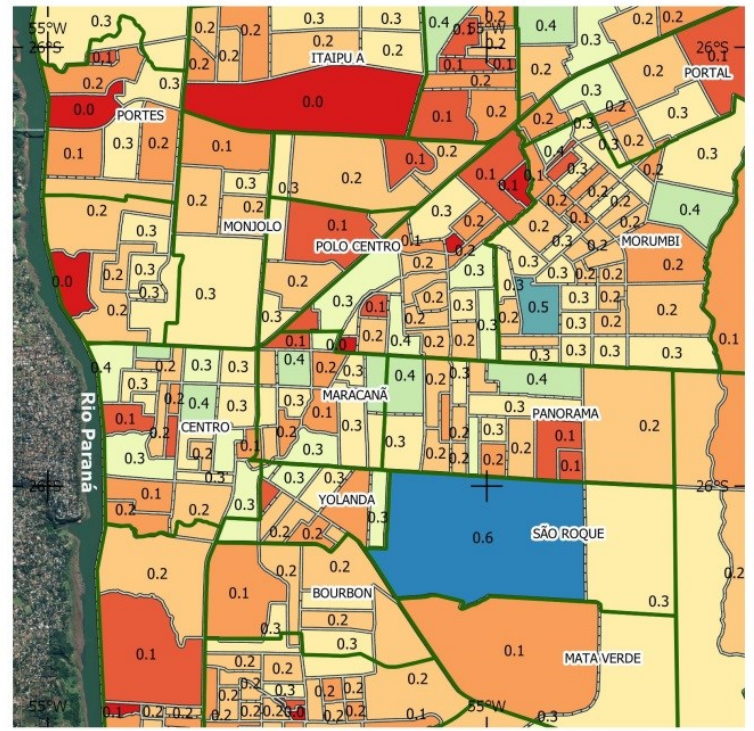

Legenda

İndice de condição de Vida_Setores censitários ص $0-0,1$

च $0,1-0,1$

口 $0,1-0,2$

口 $0,2-0,2$

口 $0,2-0,3$

勿 $0,3-0,4$

ص $0,4-0,4$

口 $0,4-0,5$

$0,5-0,5$

口 $0,5-0,6$

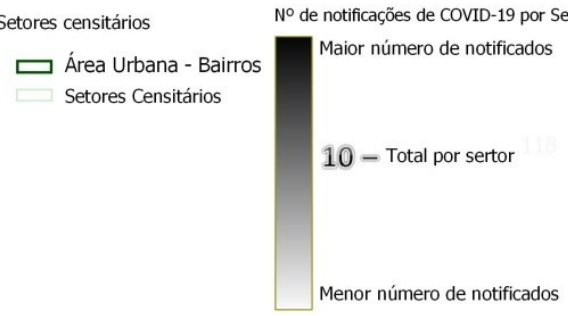

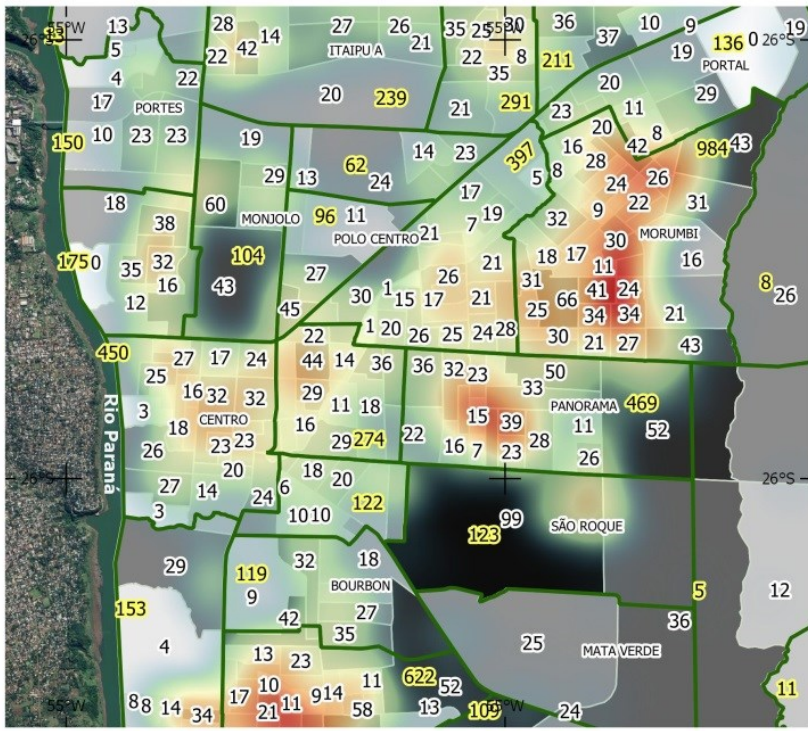

Centro_Zona Oeste - ICV / COVID - 19 (Bairros - Setores) Concentraçöes de notificaçoes

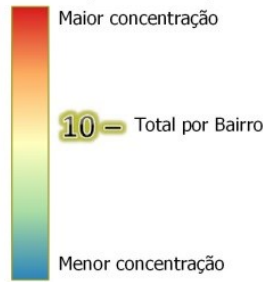

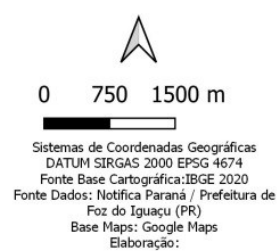

Fonte: IBGE (2020b); Base Maps (Google Maps). Organizado pelos autores.

Os ICV's com valores de 0.3 se estendem além destes para os bairros Yolanda, Monjolo e América, mas com setores nos intervalos de 0.1 a 0.2 compondo a maioria dos setores censitários. São comuns a área urbana da cidade, bairros de menor poder aquisitivo e/ou estrutura de moradia, mais a oeste, ao longo das margens do Rio Paraná. Nestes, no geral, os ICV's se apresentaram em torno de 0.1 a 0.2 .

No entanto, nas porções citadas da cidade, os ICV's baixos também estão presentes nos demais bairros, circundando aqueles que se apresentaram com valores mais elevados $(0.5-0.6)$. A proximidade das moradias de maior e menor poder aquisitivo que compõem os setores censitários da região central permitiu a mesma observação descrita para as demais regiões do município descritas 
até aqui (norte, nordeste e leste). O ICV alto de um determinado setor censitário está circunvizinho de um setor de ICV baixo, e sobre eles elevada concentração de notificações, se comparados com outros, mais distantes geograficamente.

A sobreposição das notificações de COVID - 19 e suas concentrações por setor censitário, portanto, contribui com esta observação. Exemplo são os bairros Maracanã (246) e Centro (371), setores que apresentam ICV de 0.4 ou até 0.3 , detém os maiores quantitativos de notificações e seus vizinhos respectivos, quando não da mesma quantidade de notificados estão próximos do valor.

No bairro São Roque com 123 notificados no total, foi computado setor censitário com ICV de 0.6 e número de notificados de 99 no período (apenas nele). Tem seu bairro vizinho mais a nordeste, o Panorama, 469 notificados, com concentração (mapa de calor) bem visível geograficamente, entre dois setores limítrofes. O setor que apresentou 99 (São Roque) notificados está geograficamente próximo, com pelo menos dois setores (26 e 28 ) do Panorama.

Se estendida a mesma constatação para os setores com ICV de 0.3 em comparação àqueles que obtiveram ICV menores, as manchas de concentração de casos notificados se repetem, indicando que o padrão de distribuição é o mesmo.

Analisando a porção sul da cidade (figura, 9), o bairro com ICV mais alto para alguns setores censitários ( 0.3 e 0.4$)$ foi o Carimã. Neste as concentrações de notificados se mostraram maiores nos mesmos setores (51 e 24) de ICV mais alto. Um dos setores do bairro, com elevado número de notificados (52), não possibilitou visualmente estabelecer proximidade geográfica entre as manchas de calor (concentrações) e ICV mais de outro bairro, a não ser do próprio Carimã. Neste caso, a proximidade geográfica visualizada constatada anteriormente, se mostrou maior entre setores do bairro Porto Meira.

Figura 9 - Recorte para os bairros e setores censitários da zona sul do município.

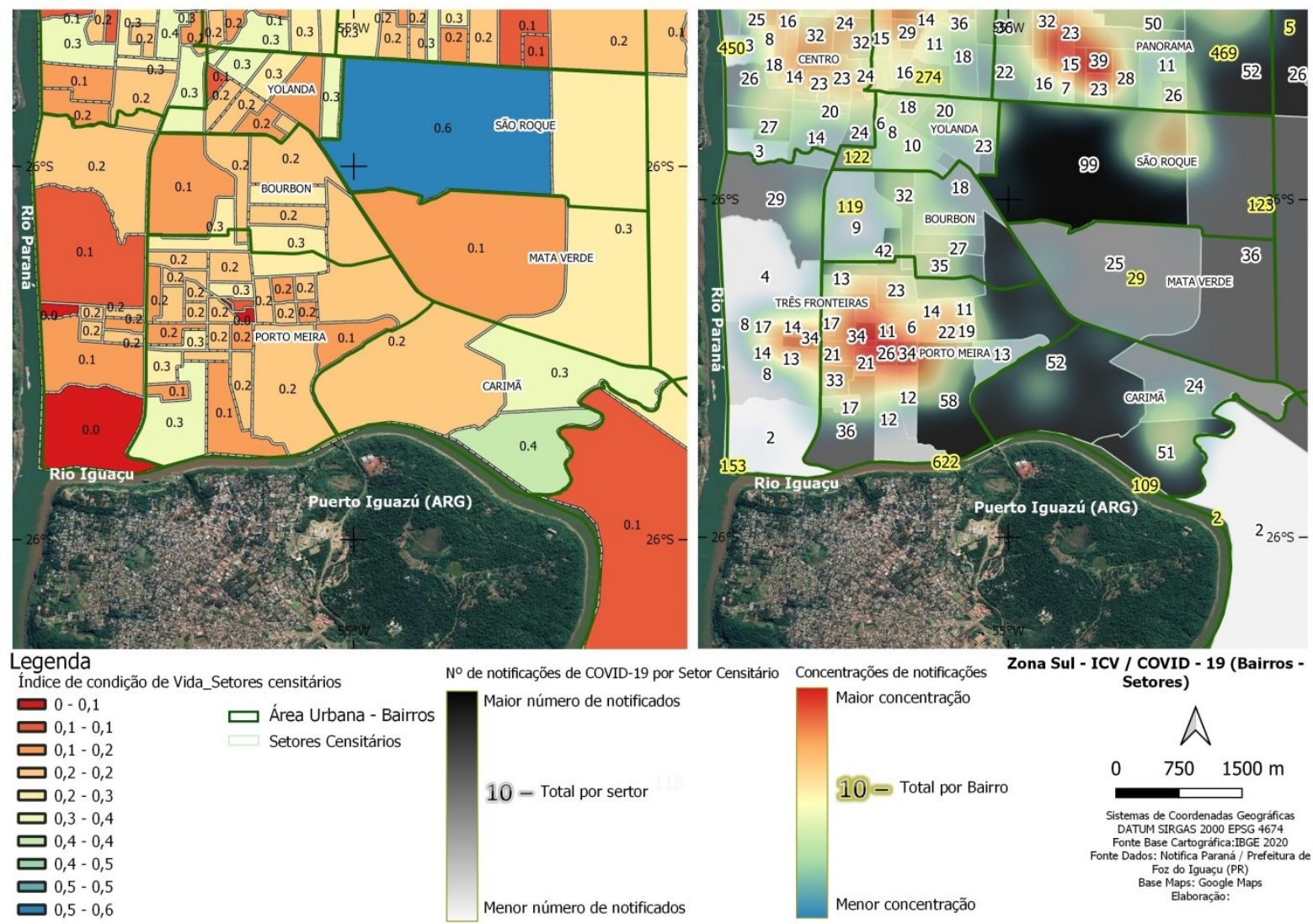

Fonte: IBGE (2020b); Base Maps (Google Maps). Organizado pelos autores. 
Por se tratar de setores de baixo ICV, o número elevado de notificações e concentrações, tem aqui um reflexo das piores condições de estrutura para o confinamento, como já aventado em argumento anterior. Outra hipótese são as relações diversas existentes entre seus residentes, com o restante da cidade, uma vez que, tais bairros comportam trabalhadores que podem atuar na região mais central da cidade ou em outras localidades. Sendo assim o argumento também é valido para as demais regiões analisadas. Os demais bairros: Bourbon, Porto Meira e Três Fronteiras, apresentaram setores censitários com valores de ICV, no geral, entre 0.1 a 0.2 , com alguns indicando ICV de 0.3 .

Destaca-se que a região sul foi a única, onde a visualização dos dados dos setores de ICV mais baixos (0.1 a 0.2) apresentaram maiores notificações, por setor, bem como, concentração geográfica dos notificados. Sendo os bairros Porto Meira e Três Fronteiras, com setores centrais a eles, os detentores dos elevados números.

\section{Principais comorbidades associadas e a correlação espacial com os setores censitários (bairros)}

Os dados coletados dos notificados com COVID- 19 retornaram até o fim de setembro de 2020, 7370 mil notificações. Deste total, $60 \%$ aproximadamente dos dados foram preenchidos com as informações da presença ou não das comorbidades associadas. Obviamente a ausência de aproximadamente $40 \%$ de dados não informados, dificulta a espacialização e demais análises das comorbidades associadas aos notificados no período. Ainda assim, é válida a apresentação dos dados preenchidos nos bancos de dados, bem como, sua espacialização com os setores censitários e bairros.

Dentre aquelas que foram elencadas no preenchimento, estão em grande maioria DNT's também observadas em outras pesquisas do gênero (NIQUINI et al., 2020; Zhou et al., 2020; Richardson et al., 2020), nas quais, têm-se apontado como fatores de risco ao agravamento da doença. Na figura 10 abaixo se observa que dos notificados a hipertensão (13\%) foi a comorbidade mais presente seguida do tabagismo $(6 \%)$, diabetes $(5 \%)$, obesidade $(4 \%)$, doença pulmonar $(4 \%)$ e vascular $(3 \%)$, como as principais existentes nos notificados no período.

Figura 10 - Porcentagem das DNT's verificadas entre os notificados do município (Março Setembro/2020).

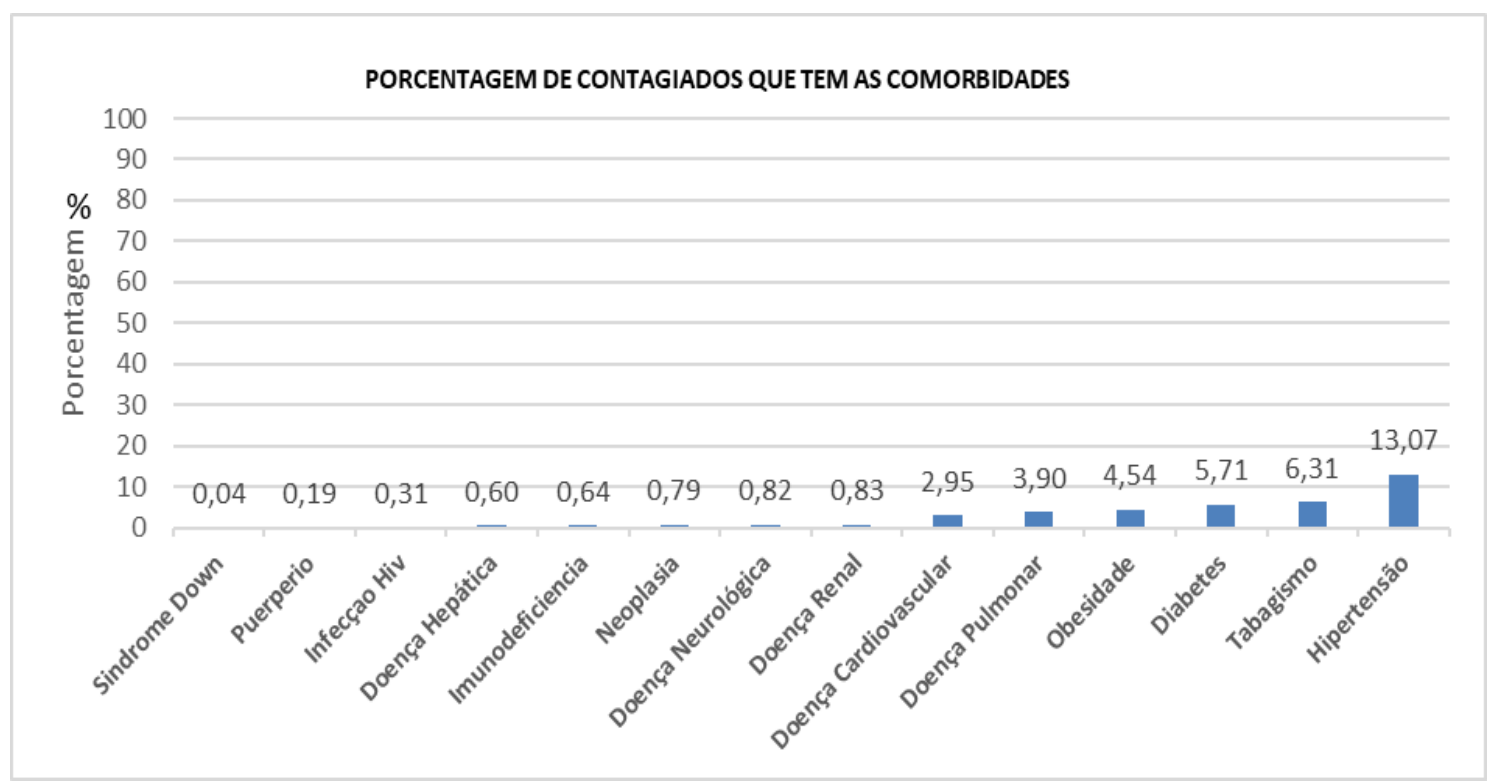

Fonte: PARANÁ (2020); FOZ DO IGUAÇU (2020b).

Mesmo o número elevado de notificados com COVID - 19 (figura 11) que não informaram (40\%) ou não disseram ter alguma das DNT's, (entorno de 40 a 50\%), credita-se tal configuração a preenchimentos autorreferidos pelos notificados. A precisão dos dados de comorbidades preenchidos DOI: http://dx.doi.org/10.14393/Hygeia17058071 $\quad$ Hygeia $\quad$ v.17 $\quad$ p.161-180, 2021 página 174 
pode impactar na acurácia desta informação, em relação à realidade de cada pessoa, bem como, do contexto do município em relação à presença destas DNT's na população.

Ao mesmo tempo, é elevada a presença de DNT's nos notificados que tiveram o preenchimento estabelecido. Hipertensão, tabagismo, diabetes, obesidade, doença pulmonar, cardiovascular, das principais listadas, somadas configuram entorno de $36 \%$ da DNT's que podem agravar quadros da COVID - 19 nos notificados. Isto por si só, evidencia uma realidade preocupante, não apenas atrelada a COVID - 19, mas um indicativo necessário para o planejamento de ações visando à saúde de toda a população município.

Figura 11 - Porcentagens dos dados obtidos ou não sobre as comorbidades.

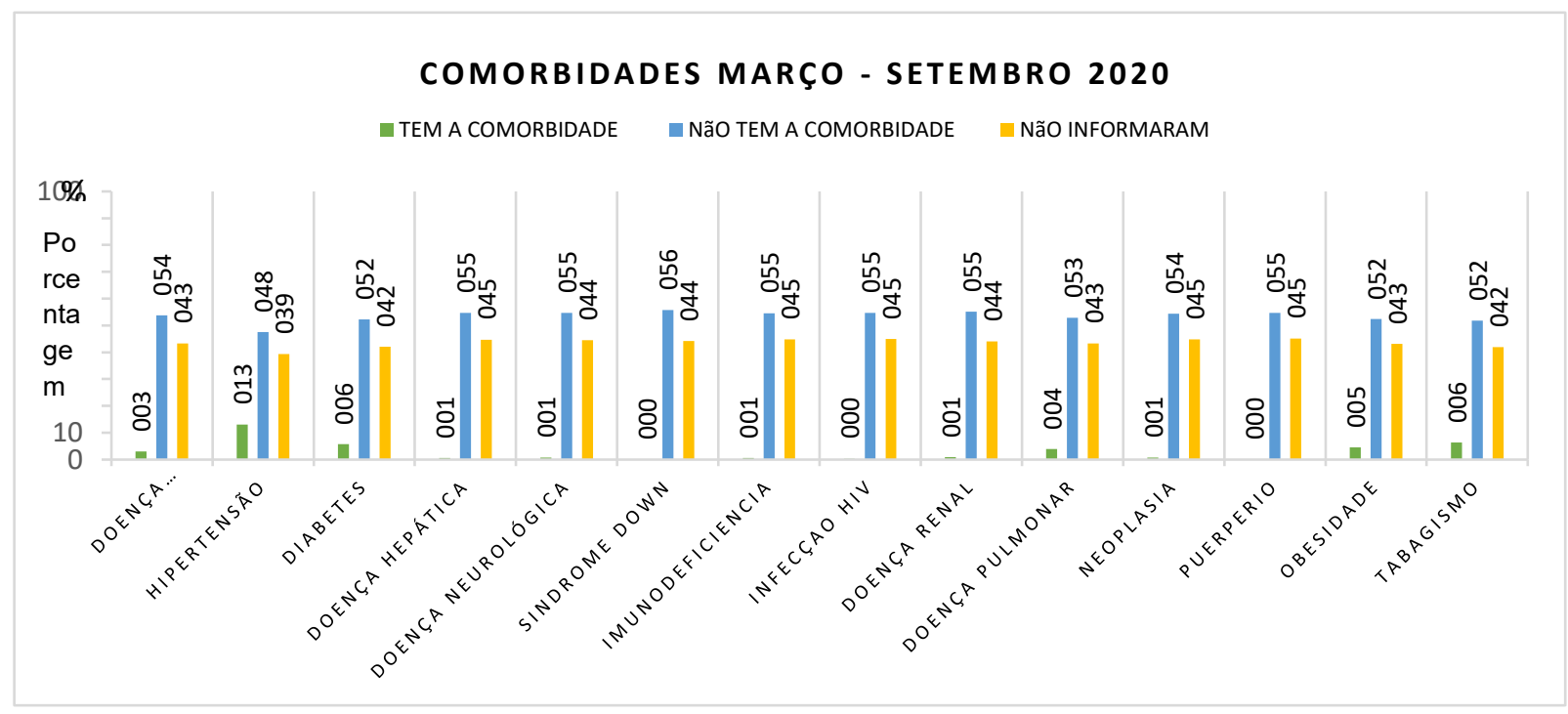

Fonte: PARANÁ (2020); FOZ DO IGUAÇU (2020b).

Ao analisar geograficamente (figura, 12) duas das principais comorbidades (hipertensão e tabagismo) existentes, por setor censitário e total por bairros, no município de Foz do Iguaçu (PR) percebe-se que o padrão de distribuição destas, não se modifica tanto em relação à análise feita entre ICV e notificados por COVID - 19. Os totais mais elevados de hipertensos, por exemplo, por setor encontram - se nas áreas de setores censitários com concentrações de ICV's mais elevados (0.4 $0.5)$ e próximos geograficamente, com outros de ICV mais baixo $(0.1-0.2)$.

As zonas leste e sul são as que apresentaram as maiores concentrações de notificados com a comorbidade hipertensão, seguidas pelas zonas norte e nordeste. A região central e zona oeste tiveram concentrações menores em relação às demais para esta comorbidade.

No caso da comorbidade tabagismo (figura 13), a sobreposição das concentrações da DNT sobre os totais por setor, embora semelhante com as demais observações já realizadas, apresentou algumas concentrações distintas nas diferentes zonas da cidade.

Sendo esta comorbidade, mais comum aos setores censitários com ICV mais baixo $(0.1-0.2)$. Esta esteve no período, presente na zona leste, nos bairros Morumbi e Campos do Iguaçu, com transição para a zona central, no bairro Panorama.

Nos bairros da zona sul, também foi alta a concentração de notificados com a comorbidade, ocorrendo, sobretudo, nos bairros Três Fronteiras e Porto Meira.

$\mathrm{Na}$ zona oeste, as maiores concentrações ocorreram nos bairros América e Monjolo e na zona norte, de forma mais distribuída e com menores concentrações em Itaipu A, Ipê e Polo Universitário. Na zona nordeste foi observado menores concentrações de notificados com a comorbidade tabagismo. 
Figura 12 - Concentração de notificados com a comorbidade hipertensão.

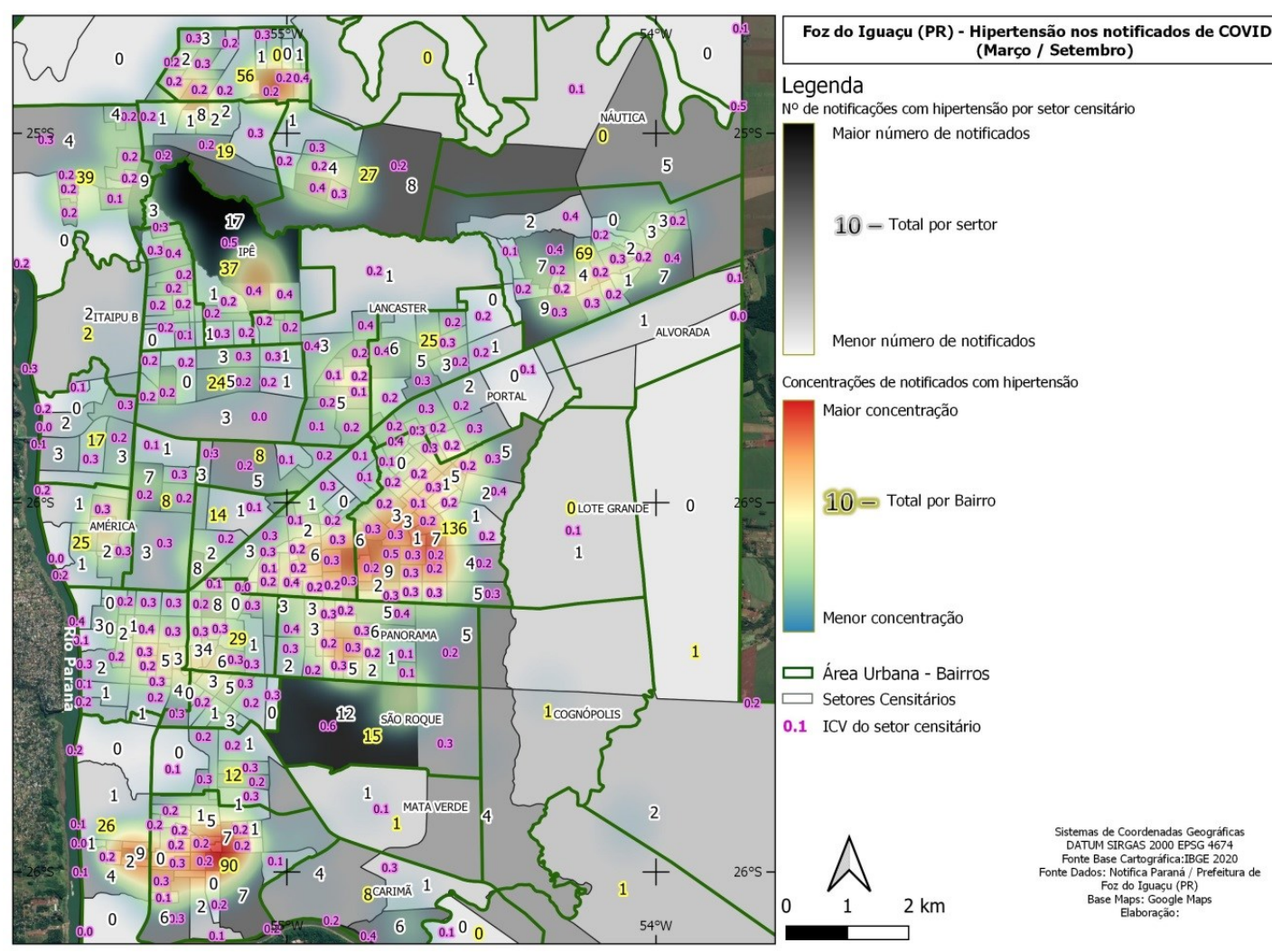

Fonte: IBGE (2020b); Base Maps (Google Maps). Organizado pelos autores.

Figura 13 - Concentração de notificados com a comorbidade tabagismo.

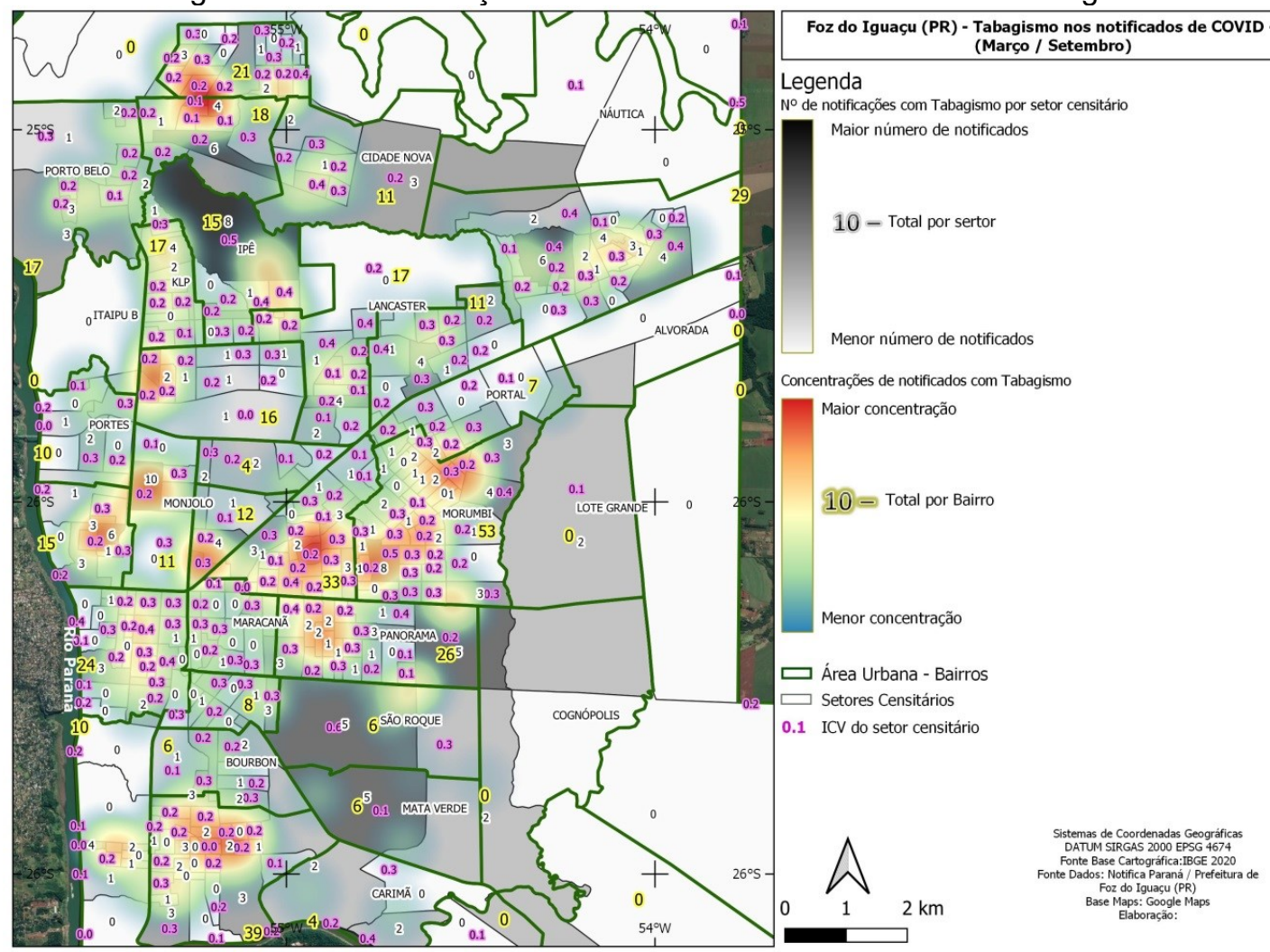

Fonte: IBGE (2020b); Base Maps (Google Maps). Organizado pelos autores. 


\section{CONCLUSÕES}

O município de Foz do Iguaçu (PR) apresentou para o ano de 2010, a partir dos dados do censo daquele ano, índice de condição de vida (ICV) relativamente baixo em grande parte dos setores censitários que compõem o município (0.1 - 0.3 no geral). Embora tenha um PIB per capta (2017) de $\mathrm{R} \$ 50.990,89$, entre os mais altos do país, o salário médio mensal dos trabalhadores formais (2018) de 2,8 salários mínimos, bem como, a renda per capta de $\mathrm{R} \$ 834,31$, ajudam a evidenciar ainda mais os valores baixos do ICV, mesmo que estes ainda reflitam dados finalizados para o ano de 2010.

Quando comparado os valores de ICV com a sobreposição dos dados das notificações absolutas e de concentrações de casos de COVID - 19, por setor censitário observou-se proximidade geográfica entre aqueles que apresentaram ICV mais elevado $(0.4-0.6)$ e seus setores circunvizinhos. Uma hipótese aventada é a de que o fluxo de serviços interdependentes existentes nos bairros onde há esta proximidade, entre setores de cada bairro possa ser uma das causas para a observação citada. Pois, no período de análise as principais atividades ligadas ao comércio (compras no Paraguai) e visitação do turismo (Cataratas entre outros) foram interrompidas até meados de agosto de 2020 , (acesso ao Paraguai ocorreu apenas no fim de outubro).

Mesmo com períodos de confinamento mais restrito, muitos serviços se mantiveram em função de estes serem caracterizados como de necessidade básica a população. $O$ conjunto de bairros em si, divididos em regiões geográficas (norte, sul, leste e oeste) concentram quase que por completo, uma rede de serviços (bancos, farmácias, lojas de materiais de construção, etc...) que atendem os bairros contidos por região. Não sendo necessário, por vezes, o deslocamento da população, a maiores distâncias, dentro da cidade, para sanar determinada demanda.

No entanto, esta hipótese necessita de melhor aprofundamento, como o levantamento de dados referente a análises de deslocamento por origem e destino, realizados principalmente, nas grandes cidades do país, através do conhecimento e catalogação dos dados dos meios de transportes utilizados pela população. Pois, para Foz do Iguaçu (PR) os deslocamentos entre bairros e externo as regiões de origem, por serviços é muito comum à cidade.

Há regiões com serviços concentrados, como prestadores de atividades ligadas a saúde e comércio na região central, onde toda a população do município se desloca em procura. Portanto, a relação de número de notificados (alta) em determinado setor censitário e sua proximidade com circunvizinho ou com pessoas oriundas de outros setores mais distantes poderia ser mais bem elucidada com pesquisas como a de origem e destino.

Com a abertura gradual das atividades e permissão controlada de circulação nos ambientes, ao longo do período, a cidade passou a receber visitantes e pessoas em busca de serviços diversos. Determinar quantitativamente e organizar modelos de previsão de contágio por redes de conexão é tarefa árdua metodologicamente. Mas uma vez, bem delineada poderia contribuir com o aprofundamento da dinâmica da cidade e dos fluxos que esta recebe, para modelagem de cenários e medidas de mitigação da doença.

A análise das principais comorbidades, mesmo limitadas a $60 \%$ de preenchimento se mostraram válidas (por conveniência não se produziu mapas para as demais comorbidades), primeiro pela possibilidade de espacialização destas, por setor censitário. Isto abre possibilidades de análises mais expandidas das DNT's em diversos contextos e não apenas neste relacionado ao COVID-19.

Quando observado o recorte municipal para as duas das DNT's com maior percentual no município, percebeu-se a mesma lógica de espacialização entre setores de ICV alto e aqueles contíguos de ICV baixo, com diferenças pontuais entre alguns bairros. No entanto, como já ressaltado anteriormente, a referida correlação necessita de outros elementos metodológicos para aprofundamento das constatações.

Desta forma, a pesquisa aqui delineada conseguiu apresentar um contexto de estruturação da condição de vida da população de Foz do Iguaçu (PR), relacionada a um recorte no tempo (2010). Mas, mesmo a distância de dez anos, em relação às variáveis utilizadas para a montagem do ICV, indicou uma realidade provável a muitos residentes no município. A correlação espacial estabelecida entre os ICV's por setor censitário e os dados de notificação de COVID - 19 no período de marçosetembro de 2020 se mostrou relevante como ferramenta de análise espacial e de conhecimento de aspectos relacionados à saúde da população do município, em tempos de pandemia (ou sindemia se considerado as DNT's e sua relevância para análise). Cabe agora, tecer novas formas de pesquisa e avaliação dos dados, para que estes possam ser utilizados com eficácia para tomadas de decisão. 


\section{AGRADECIMENTOS}

Agradecimentos a Secretaria de Saúde de Foz do Iguaçu (PR) e a PROEX - UNILA (instituição financiadora das bolsas de extensão vinculadas ao Projeto Institucional: Enfrentamento ao Coronavírus (SARS-CoV-2): Ações de enfrentamento - GT 6 - Projeções.

\section{REFERÊNCIAS}

BEZERRA, Anselmo César Vasconcelos et al . Fatores associados ao comportamento da população durante o isolamento social na pandemia de COVID-19. Ciênc. saúde coletiva, Rio de Janeiro, v. 25, supl. $1, \quad$ p. 2411-2421, June 2020.Disponível em: $<$ http://www.scielo.br/scielo.php?script=sci_arttext\&pid=S1413-

81232020006702411\&lng=en\&nrm=iso>. Acesso em: 30 Outubro de 2020. Epub June 05, 2020. https://doi.org/10.1590/1413-81232020256.1.10792020

BRASIL. Ministério da Saúde. Sobre-a-doenca. Brasília, 2001. Disponível em:< https://coronavirus.saude.gov.br/sobre-a-doenca>. Acesso em: 01 de Outubro de 2020a.

BRASIL. MINISTÉRIO DA SAÚDE. DATASUS - Banco de dados do Sistema Único de Saúde. Disponível em: www.datasus.gov.br. Acesso em: 06/10/2020b.

CASTELLANOS, P. L. Proyecto: sistemas nacionales de vigilancia de la situación de salud según condiciones de vida y del impacto de las acciones de salud y bienestar. Washington: Organización Panamericana de la Salud, 1994.

FARIAS, H.S. Índice de condição de vida e saúde (ICV'S): uma proposta de espacialização da vulnerabilidade social da população da região metropolitana do Rio de Janeiro. Geografia em Questão. V.07, N. 01, ISSN 2178-0234. 2014.

FOZ DO IGUAÇU. Decreto $\mathrm{n}^{\circ} \mathbf{2 8 . 0 0 0}$, de 30 de março de 2020. Declara estado de calamidade pública no Município de Foz do Iguaçu, em decorrência da pandemia do Novo Coronavírus. Diário Oficial No 3.821 de 30 de março de 2020a.

FOZ DO IGUAÇU. Boletim. Disponível em: https://www.amn.foz.br/posts/?dt=18-de-marco-de-2020cldFMFRVWVdrMStjODhTUIRaZ1kvdz09. Acesso em: 07/10/2020b.

FOZ DO IGUAÇU. Decreto $n^{0}$ 22.166, de 14 de maio de 2013. Dispõe sobre a Estrutura Administrativa relativa às unidades de terceiro nível hierárquico, subordinadas às diretorias. Disponível em:< https://leismunicipais.com.br/a2/pr/f/foz-do-iguacu/decreto/2013/2216/22166/decreton-22166-2013-dispoe-sobre-a-estrutura-administrativa-relativa-as-unidades-de-terceiro-nivel-

hierarquico-subordinadas-as-diretorias-que-passa-a-vigorar-na-forma-do-disposto-neste-decreto-bemcomo-a-implantacao-do-sistema-de-siglas-da-prefeitura-municipal-de-foz-do-iguacu>. Acesso em 6 jun. 2020.

FOZ DO IGUAÇU. Lei complementar $n^{0} .303$, de 20 de dezembro de 2018. Dispõe sobre a criação, delimitação e denominação de Bairros no Município de Foz do Iguaçu e dá outras providências. Diário Oficial do Município, Foz do Iguaçu, PR, 21 dez. 2018. Disponível em: <https://leismunicipais.com.br/a1/pr/f/foz-do-iguacu/lei-complementar/2018/31/303/lei-complementarn-303-2018-dispoe-sobre-a-criacao-delimitacao-e-denominacao-de-bairros-no-municipio-de-foz-doiguacu-e-da-outras-providencias?q=303>. Acesso em 15 ago. 2020.

FOZ DO IGUAÇU. Decreto $\mathbf{n}^{0}$ 27.712, de 2 de dezembro de 2019. Altera dispositivos do Anexo do Decreto $n^{0} 22.166$, de 14 de maio de 2013 e alterações, que trata da Estrutura Administrativa relativa às unidades de terceiro nível hierárquico. Diário Oficial do Município, Foz do Iguaçu, PR, 3 dez. 2019. Disponível em: <https://leismunicipais.com.br/a2/pr/f/foz-do-iguacu/decreto/2019/2771/27712/decreton-27712-2019-altera-dispositivos-do-anexo-do-decreto-n-22166-de-14-de-maio-de-2013-e-alteracoesque-trata-da-estrutura-administrativa-relativa-as-unidades-de-terceiro-nivel-hierarquico>. Acesso em 1 out. 2020.

FUNDAÇÃO JOÃO PINHEIRO. Condições de vida nos municípios de Minas Gerais: 1970, 1980 e 1991. Belo Horizonte: FJP, 1996.

GALINDO, J.; ARROYO, L. Os mapas da pandemia revelam as desigualdades na América Latina. EL PAís, 2020. Disponível em: <https://brasil.elpais.com/internacional/2020-08-04/os-mapas-dapandemia-revelam-as-desigualdades-na-america-latina.html>. Acesso em: 30, Outubro de 2020.

DOI: http://dx.doi.org/10.14393/Hygeia17058071 Hygeia $\quad$ v.17 $\quad$ p.161-180, 2021 página 178


GRAGNANI, J. Por que o coronavírus mata mais as pessoas negras e pobres no Brasil e no mundo. BBC BRASIL, 2020. Disponível em:< https://www.bbc.com/portuguese/brasil-53338421>. Acesso em: 28/09/2020.

HORTON, R. Offline: COVID-19 is not a pandemic. COMMENT| VOLUME 396, ISSUE 10255, P874, SEPTEMBER 26, 2020. https://doi.org/10.1016/S0140-6736(20)32000-6

INSTITUTO BRASILEIRO DE GEOGRAFIA E ESTATÍSTICA - IBGE. Catalogo de download geociências. Disponível em: <https://downloads.ibge.gov.br/downloads_geocien cias.htm>. Acesso em: 20/09/2020a.

INSTITUTO BRASILEIRO DE GEOGRAFIA E ESTATÍSTICA - IBGE . CENSO DEMOGRÁFICO 2010: características da população e dos domicílios: resultados do universo. In: IBGE. Sidra: sistema IBGE de recuperação automática. Rio de Janeiro, 2011a. Disponível em: <http://www.sidra.ibge.gov.br/cd/cd2010universo.asp?o=5\&i=P>. Acesso em:: 02/09/2020b.

INSTITUTO BRASILEIRO DE GEOGRAFIA E ESTATÍSTICA - IBGE. Regiões de influência das cidades setor Saúde 2018. Rio de Janeiro: IBGE; 2018. Disponível em:< https://mapasinterativos.ibge.gov.br/covid/regic>. Acesso em: 20/09/2020c.

MARINO, A.; KLINTOWITZ, D.; BRITO G.; ROLNIK R.; SANTORO P.; MENDONÇA P. Circulação para trabalho explica concentração de casos de Covid-19. LABCIDADE. São Paulo, 30 de junho de 2020. Disponível em: http://www.labcidade.fau.usp.br/circulacao-para-trabalho-inclusive-servicosessenciais-explica-concentracao-de-casos-de-covid-19/. Acesso em: 01/08/2020.

NIQUINI, R. P. et al. SRAG por COVID-19 no Brasil: descrição e comparação de características demográficas e comorbidades com SRAG por influenza e com a população geral. Cadernos de Saúde Pública [online]. v. 36, n. 7 [Acessado 1 Novembro 2020], e00149420. Disponível em: <https://doi.org/10.1590/0102-311X00149420>. ISSN 1678-4464. https://doi.org/10.1590/0102$\underline{311 \times 00149420}$

PARANÁ. SECRETÁRIA DE SAÚDE. Sistema de notificação de casos suspeitos de COVID-19: Notifica COVID-19. Disponível em: < https://covid19.appsesa.pr.gov.br/login de acesso/>. Acesso em: 30/09/2020.

PNUD - PROGRAMA DAS NAÇÕES UNIDAS PARA O DESENVOLVIMENTO; IPEA -INSTITUTO DE PESQUISA ECONÔMICA E APLICADA; FUNDAÇÃO JOÃO PINHEIRO. Atlas de desenvolvimento humano do Brasil de 2020. Disponível em: <http://www.atlasbrasil.org.br/2020/>. Acesso em: 09/09/2020.

RAMBO, A. G; et. al. O Índice de Condições de Vida (ICV): construindo metodologias de análise e avaliação de dinâmicas territoriais do desenvolvimento rural. Revista em Gestão, Inovação e Sustentabilidade - Brasília, v. 1, n. 1, p. 68-94, dez. 2015.

RICHARDSON S, HIRSCH JS, NARASIMHAN M, CRAWFORD JM, MCGINN T, DAVIDSON KW, et al. Presenting characteristics, comorbidities, and outcomes among 5700 patients hospitalized with COVID-19 in the New York City area. JAMA 2020; 323:2052-59. https://doi.org/10.1001/jama.2020.6775

SINGER M. A Dose of Drugs, a Touch of Violence, A Case of AIDS: Conceptualizing the SAVA Syndemic". Free Inquiry in Creative Sociology. 24 (2): 99-110. 1996.

SINGER, M.C. Introduction to syndemics: a systems approach to public and community health. Jossey-Bass, San Francisco, 2009.

SINGER, M.C; CLAIR, S. Syndemics and public health: reconceptualizing disease in bio-social context. Med Anthropol Q. 2003; 17: 423-441. https://doi.org/10.1525/maq.2003.17.4.423

SINGER M, BULLED N, OSTRACH B. Syndemics and human health: implications for prevention and intervention. Ann Anthropol Pract ,2012; 36: 205-11. https://doi.org/10.1111/napa.12000

SINGER, M, BULLED, N, OSTRACH, B; MENDENHALL, E. Syndemics and the biosocial conception of health. The Lancet 2017; 389(10072): 941-950. https://doi.org/10.1016/S0140-6736(17)30003-X

TEIXEIRA, C. F. et al. SUS, modelos assistenciais e vigilância da saúde. Informe Epidemiológico do SUS, VII(2): 8-28, 1998. https://doi.org/10.5123/S0104-16731998000200002 
ZHOU F, YU T, DU R, FAN G, LIU Y, LIU A, et al. Clinical course and risk factors for mortality of adult inpatients with COVID-19 in Wuhan, China: a retrospective cohort study. Lancet 2020; 395:1054-62. https://doi.org/10.1016/S0140-6736(20)30566-3

WAQUIL, P. D. et al. Proposição do Índice de Condições de Vida. Porto Alegre:PGDR/UFRGS, SDT/MDA, 2007. (Relatório de pesquisa). 